\title{
An Internal Model-Based PID Control for Smart Shot Peening Operation
}

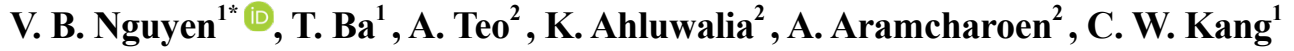 \\ ${ }^{1}$ Fluid dynamics department, Institute of High-Performance Computing, A*STAR, Singapore \\ ${ }^{2}$ Data-Driven Surface Enhancement Group, Advanced Remanufacturing and Technology Center, A*STAR, Singapore \\ E-mail: nguyenvb@ihpc.a-star.edu.sg
}

Received: 3 May 2021; Revised: 16 July 2021; Accepted: 4 August 2021

\begin{abstract}
Current control systems for the shot peening operation merely rely on old technologies, which often require repetitive processes to obtain pre-validated Almen systems to guide industrial productions. These designs for the manufacturing paradigm are not efficient for complicated workflows in modern manufacturing operation. Thus, in this study, we propose a practical model-based control system to address the issues; especially for a smarter and automated shot peening machine. In particular, the closed-loop control system development utilizes a model-based proportionalintegral-derivative (PID) control technology and extreme gradient boosting (XGBOOST) machine learning algorithm. The control system includes an internal process model, a proxy model, a model-based PID controller, and pressure sensors with a low-pass filter for feedback control. The developed control system is integrated into a physical shot peening machine for on-site control validation and demonstration. In both in-silico and on-site control demonstrations, the obtained control performance is stable, robust, and reliable for different operational conditions. The measurement intensities are very close to targeted setting intensities. All the differences are smaller than the industrial threshold of $( \pm 0.01 \mathrm{mmA})$. It implies that the control system can use in industrial peening operations without the need for Almen system development for operational guidance. In other words, the control system can significantly reduce the total cost of the actual production by eliminating the cost, time, and labor of the iterative trials to build the Almen system.
\end{abstract}

Keywords: shot peening, control system, internal process model, proxy model, PID, auto tuning

\section{Introduction}

The shot peening process is widely used in different industrial applications to improve the fatigue life cycle of the components by introducing a thin layer of compressive residual stress near-surface [1-3]. In the shot peening operation, the targeted peening intensity is an important output parameter among other outputs (e.g., peening coverage [4], surface roughness [5], distortion of component [6], etc.), which needs to achieve after each peening operation. The peening intensity is directly related to the kinetic energy of the shot stream transferred to the workpiece [7], which is often determined using the Almen system and standard procedures. In which, a saturation curve is plotted using at least four values of measured arc heights and corresponding exposure times [8]. In practice, the Almen system development stage often takes a lot of production effort to establish process parameters for a targeted intensity. It means that the Almen system development stage is time-consuming, labor effort, material consumption, and cost expensive. Thus, a practical

Copyright (C2021 V. B. Nguyen, et al.

DOI: https://doi.org/10.37256/dmt.112021908

This is an open-access article distributed under a CC BY license

(Creative Commons Attribution 4.0 International License)

https://creativecommons.org/licenses/by/4.0/ 
and more advanced control system for shot peening machines is still awaited to upgrade the existing control system for a smarter and automated operation, which can eliminate the Almen system development stage. Thus, it can greatly reduce the total cost, time, and labor for future actual peening operations.

The proportional-integral-derivative (PID) control technology has been widely used in many industrial applications [9], such as control additive manufacturing processes [10-12], engineering chemistry process design and development [13], powder technology [14], welding technology [15], aerospace engineering [16], and automotive engineering [17], etc. The usage of PID control has also shown a great reduction in cost, time, and labor, as well as improvement in quality, stability, and productivity of manufacturing production [10]. Two popular methods for PID controller design and tuning are the direct and indirect methods [18]. In the direct method, controller parameters are directly fine-tuned from feedback data during operation. The challenges of this method are to determine suitable characteristics that represent relevant properties of the control system, and a proper way of modifying the controller parameters to obtain setting objective(s) [18]. Thus, the direct method might not be a practical approach for the complex and highly nonlinear dynamical system. In the indirect method, a dynamical process model is often utilized to evaluate the controller parameters. Specifically, Åström and Hägglund [19] developed a control 'tune-in' algorithm to compute controller parameters from the process model parameters. In which, the dynamical process model can be a theoretical model or data model from measurements of the input(s) and output(s) [13]. The indirect control performance is often robust, accurate, and stable as the control parameters are accurately and adaptively evaluated from the dynamical model during the operation. Thus, to upgrade the current control system [20], the model-based PID control technology is a good and reliable choice for a smarter and automated shot peening machine.

In model-based PID controller development, three important features of the PID controller are auto-tuning, gain scheduling, and adaptation control parameters. These common features are often employed in the controller design application [18]. The auto-tuning is a method where the controller is automatically tuned basing on demands from the user (e.g., using process model parameters [19, 21], transfer function [22], and sampling data and process response [23], and maximum likelihood estimation and multi-rate sample system for online model parameter identification [24], etc.). This method often requests to provide a lot of information about the controller structure, sampling rate, filter time constants, control gain, etc., to give an appropriate control parameter suggestion. The gain scheduling is often employed to change the control parameters relying on the measurement operating conditions (e.g., fuzzy gain scheduling [25], linear model parameters with derivations [26]). The scheduling variable can be a measurement signal, controller output, or an external signal [26]. This method is a very effective method for controlling systems whose dynamics change with the operating conditions. We also can combine the gain scheduling method with the auto-tuning method for easy use. The adaptive control method adaptively changes control parameters to compensate for any change in process dynamics and/or disturbances. Such as Thabet et al. [27] developed the adaptive control based on adaptive Smith predictor. Chertovskikh et al. [28] designed a pre-used trained neural network for online auto-tuning to obtain smooth adaptive control. Kramer et al. [29] employed an online adaptive reduced model to design adaptive model-based control. He et al. [30] developed real-time adaptive control using fuzzy self-tuning, while Chang et al. [31] used auto-tuning neurons. And Poulin et al. [32] solved the minimization problem with the integral of the time-multiplied absolute value of error (ITAE) criterion for adaptive control parameters in real-time process control. The adaptation method is often a prerequisite for using a feedforward control system. Generally, for practical applications, the choice of these controller features mainly depends on the controller performance and nature of the dynamical process. A controller with fixed parameters and conservative tuning can use for the reserved process system. A controller with a fixed set of control parameters obtained from the auto-tuning method often applies to constant process dynamics. An adaptive controller is suitable for a dynamical process and/or disturbance, where variations are dynamically changing in time and cannot be measured and/or predicted [18]. In addition, for a process system with measurable or predictable variation, a gainscheduling controller is a good choice as it can provide a simpler control design and more robust performance than continuous adaptation [18]. In addition, the auto-tuning controller can be employed to build a gain schedule controller. Particularly, for shot peening application, to choose a suitable control method, we need to understand characteristics and physical insights into the dynamical peening process to ensure that the developed system is controllable and measurable.

In shot peening operation, peening intensity is strongly dependent on operational input parameters (analytical approach [33], numerical approach [34], and experimental and optimization approach [35]), which include inlet air pressure, media flow rate, peen size, nozzle geometry, hose system, stand-off distance, impact angle, etc. Inlet air 
pressure and media flow rate can be controlled to achieve targeted intensity and coverage. So that, both inlet pressure and media flow rate can be chosen as manipulation variables in controller design. For observation variables, popular measurement sensors (e.g., pressure sensor, shot meter, high-speed camera, reaction force sensor, acoustic emission sensor, accelerometer sensor, etc.) are used in shot peening applications to relatively measuring the kinetic energy of media stream [20]. We can choose a suitable sensor for the practical real-time feedback control system. In addition to the selection of control variable(s) and measurement variable(s), the determination of a suitable control method for a highly nonlinear and dynamic peening process is another important step.

In controller design and parameter tuning, the internal model control (IMC) - PID approach provides a suitable framework for satisfying three objectives of controller design, which are control tuning, simplicity, and optimality. Particularly, Garcia and Morari first introduced internal model control (IMC) in references [36, 37]. And Economou et al. [38] further developed and extended to nonlinear process, while Cheng and Chiu applied adaptive IMC design for nonlinear process control [39]. Using IMC design, controller complexity relies entirely on the process model complexity and designed controller performance. The main advantage of IMC controller design is to provide valuable insights regarding controller-tuning effects on both performance and robustness. The IMC design procedure leads naturally to the need for a first-order plus dead time model to augment PID controller structure and performance. In which, the adjustable parameter $\varepsilon$ is directly related to the response speed, while $1 / \varepsilon$ is approximately equal to the bandwidth of the closed-loop control system. Integration of an accurate process model into PID controller can support improving the performance of linear or nonlinear process control with constraints and multivariate interactions. Thus, in this study, we employ the PID model-based controller design procedure to develop a practical feedback control system for a smarter shot-peening machine based on a relevant sensor measurement variable. The development only focuses on the output of peening intensity, while the coverage will address in another study.

\section{Model developments}

In actual peening operation, the inlet air pressure and media flow rate are the main inputs that are often manipulated to attain the main targets of any peening process, which are the intensity and coverage. However, in this study, we only focus on the peening intensity, while coverage will be considered in another future study. In addition, the peening intensity is a statistic parameter, which only can be measured upon the peening process completion. Thus, the air pressure at the nozzle is employed as an intermediate variable for real-time monitoring, instead. As such, an internal process model is developed to link the inlet air pressure to air pressure at the nozzle to describe the dynamics of the peening process, while a proxy model is developed to translate the target intensity into a pressure reference set-point at the nozzle for real-time tracking. The followings are the details of model developments.

\subsection{Experimental trials for model development}

In this study, the shot peening machine (from Abrasive Engineering Pte Ltd.) is used in experimental trials and on-site control later. Figure 1(a) shows the general schematic diagram of the system setup. In which, the four pressure sensors (P4, P1, P2, and P3) are placed for data collection and real-time monitoring of the pressure at the inlet and on the nozzle. The pressure sensor (P4) measures air pressure at the inlet, while the sensors (P1, P2, and P3) measure air pressure along with the nozzle for model development. Figure 1(b) shows a typical pressure sensor used in this study. The piezoresistive pressure sensor is an accurate and compact sensor from KISTLER Company. This pressure sensor can measure the absolute value of air pressure for a range from 0.0 to $10.0 \mathrm{bar}$ and temperature up to $200^{\circ} \mathrm{C}$. It should be noted that the pressure sensors are chosen for model and control development based on the sensor down-selection process. In which, the sensor down-selection process is carefully performed to choose the most suitable sensor and relevant measurement variable, but will not describe in this paper.

For internal process model development, a total of 10 experimental trials are performed for the step increment and decrement of inlet air pressure from 20 to $54 \mathrm{psi}$ (from 1.3789 to 3.7232 bar) of 5 different media flow rates and 2 peen types (ASR 70 and ASR 230). In particular, a step of 2 psi (0.13789 bar) is set for the increment and decrement of the inlet air pressure (P4) to collect the air pressure at P1, P2, and P3 in 10 seconds. Figure 2(a) shows the design of the input signal of the inlet air pressure, while Figure 2(b) is the measurement results of the ASR 70 peen type and media 
flow rate of $3 \mathrm{~kg} / \mathrm{min}$. Obtained results show that the measurement data always contains a certain level of noise. The noise is higher for a higher media flow rate and larger peen size. To build the process model, the Kalman filter is utilized to cancel out the high-frequency noise from the measurement data. Details of process model development will present in subsection 2.2.

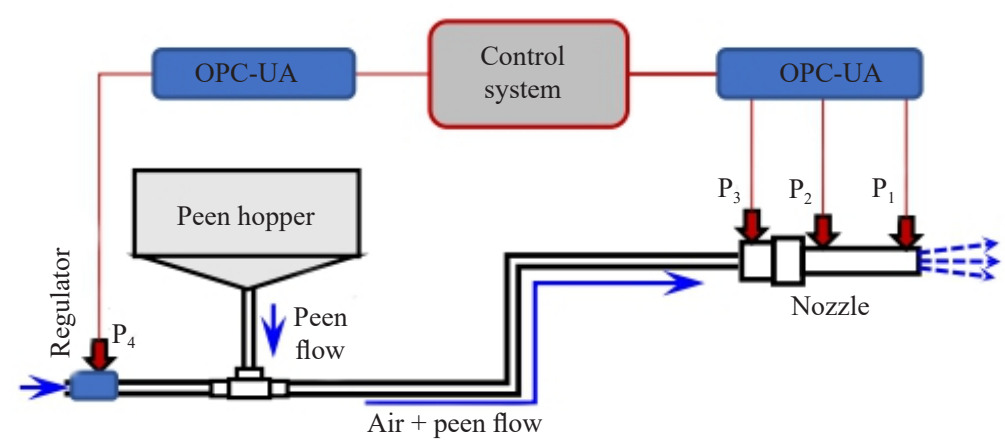

(a)

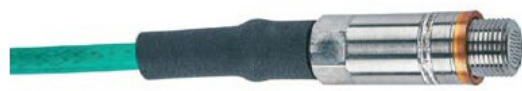

Piezoresistive pressure sensor Type 4007D...DS

(b)

Figure 1. Experimental setup: (a) General schematic diagram of system setup and (b) used piezoresistive pressure sensor for data collection and feedback control.

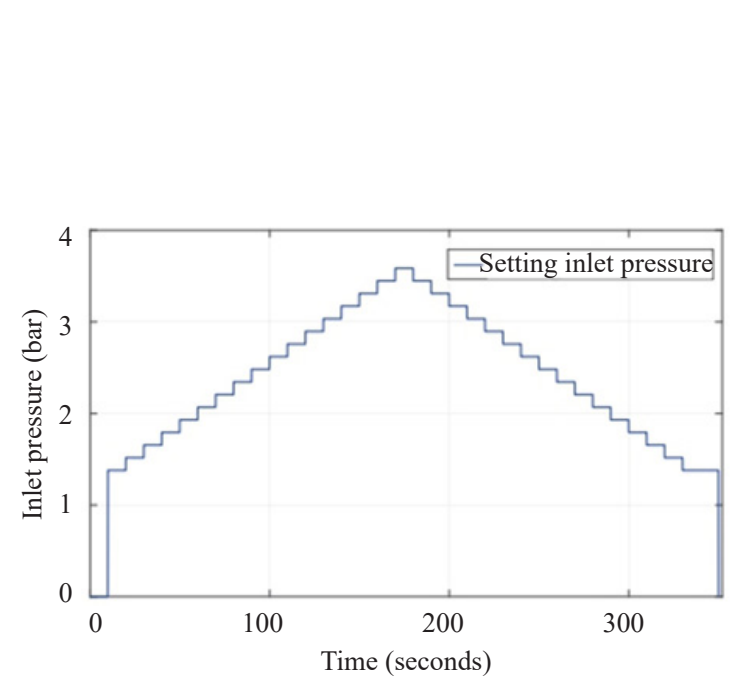

(a)

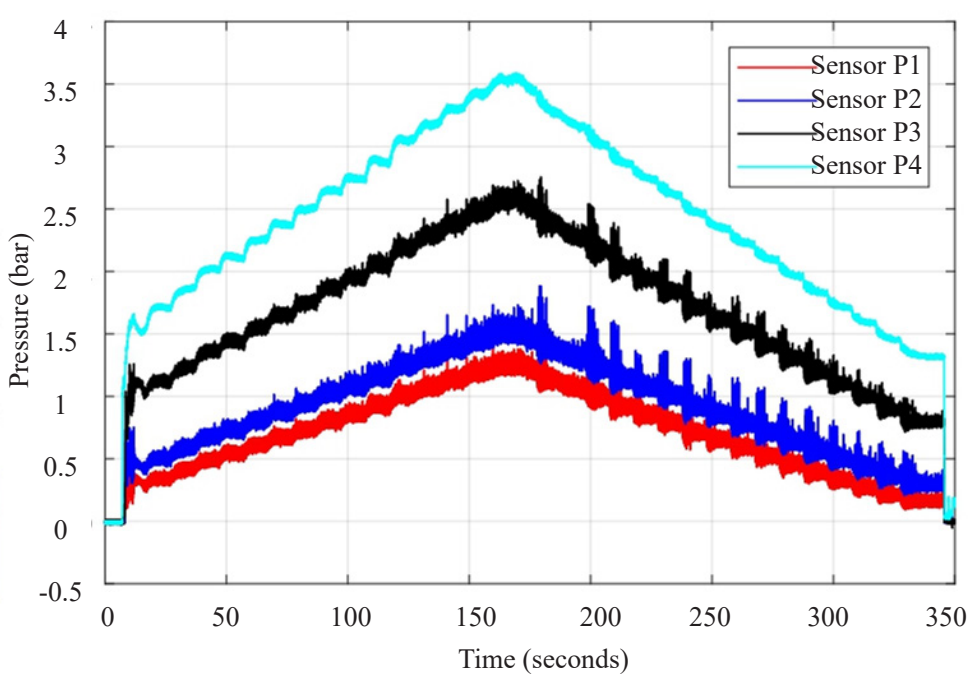

(b)

Figure 2. (a) Design signal of inlet air pressure for obtaining the measurement air pressure on nozzle, and (b) measurement pressure at P1, P2, P3, and P4 for ASR 70 peen type and media flow rate of $3.0 \mathrm{~kg} / \mathrm{min}$.

For proxy model development, a total number of 20 operational conditions are set in experimental trials to collect measurement data of inlet pressure, media flow rate, peen size, pressure on nozzle, and intensity. These 20 sets of operating conditions are combinations of four values of inlet air pressure (20,30, 44, and 54 psi) and five values of media flow rate $(1.0 ., 2.0,3.0,4.0$, and $5.0 \mathrm{~kg} / \mathrm{min})$. Each operation condition is repeated at least four different exposure times to build a saturation curve for determining one value of the intensity, while another four repeated times are used for the validation to ensure that the obtained intensity is accurate (error $\pm 0.01 \mathrm{mmA}$ ) and repeatable. In this study, the peening intensity is measured using Almen gage to express the arc height measurement of the peened Almen strip type A. The unit of peening intensity is often denoted as mmA. Details of the standard procedure for peening intensity measurement are presented in reference [7]. All these experiments are performed for two peen types (ASR 70 and ASR 230). The results of measurement intensities are shown in Figure 3; (a) is for ASR 70 and (b) is for ASR 230. The 
obtained results show that the intensity is smaller for the smaller peen type (ASR 70) with the same inlet air pressure. Finally, the mean value of measurement intensity is evaluated for each operating condition to using in model training.

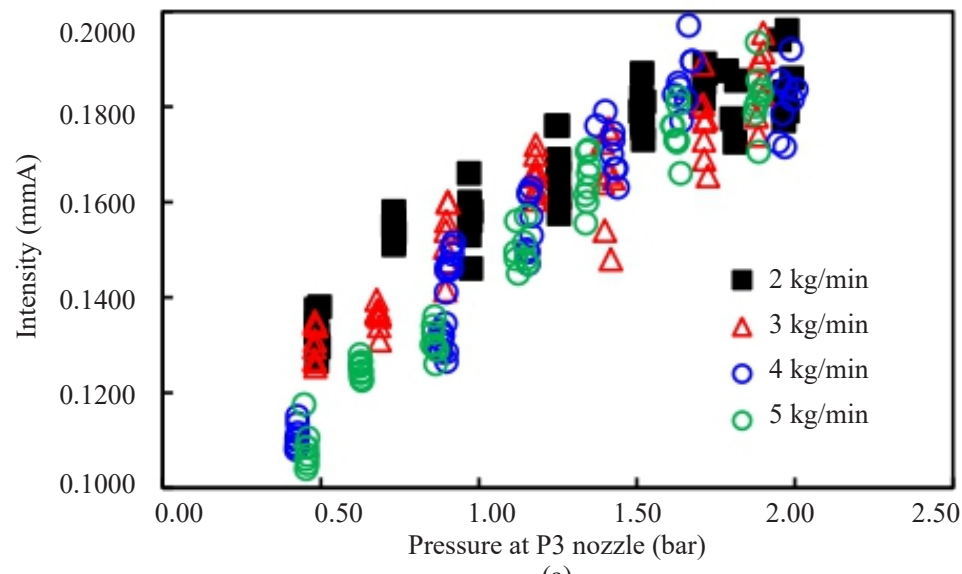

(a)

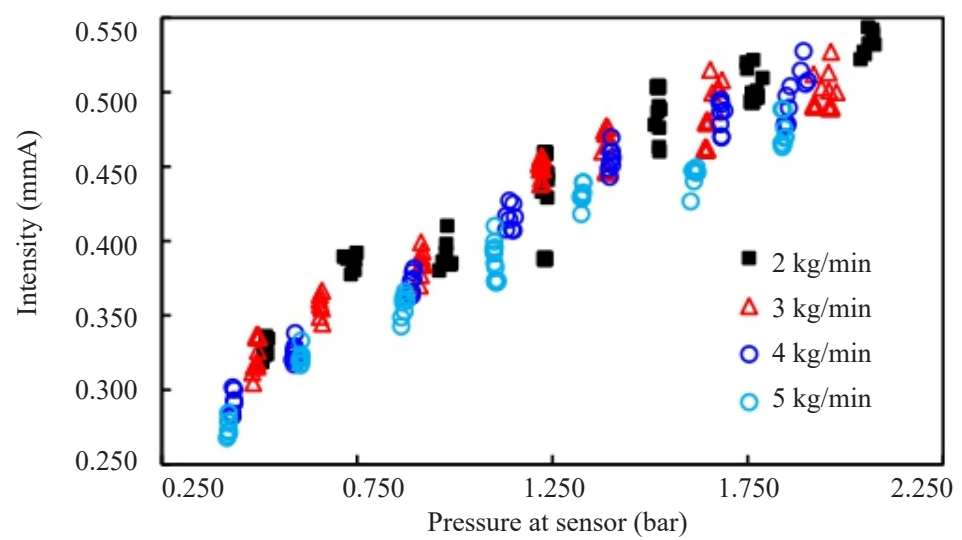

(b)

Figure 3. Measurement intensity of different operational conditions: (a) ASR 70 peen type and (b) ASR 230 peen type.

\subsection{Internal process model development}

There are different methods to develop an internal process model for control system development in manufacturing systems (e.g., regression method with a list of candidate functions [40], optimization method [41], and neural network and machine learning [42], etc.). In this study, to develop an internal process model for the PID controller development, we assume that the change of state variable in time can be expressed in the form of first-order plus dead-time model (FOPDT) as bellow:

$$
\tau_{p} \frac{d y(t)}{d t}=f(y, m, t)+K_{p} u\left(t-\theta_{p}\right)
$$

In this expression, $y(t)$ is process variable (also called measurement variable or pressure on nozzle, $\left.y \in R^{1}\right), f(y, m, t)$ is a function of pressure on nozzle, media flow rate and time, $u(t)$ is input variable (also called as manipulated variable or inlet air pressure), $\tau_{p}$ is process time constant, $K_{p}$ is process gain, and $\theta_{p}$ is process dead time. To build the process model in the form of Equation (1) for the existing shot peening machine, we use the set of data of inlet air pressure 
$(u(t))$, media flow rate $(m)$, and air pressure on the nozzle $(y(t))$, which are varying in time. These collected data cover the whole range of control windows (e.g., $u_{\min }<u(t)<u_{\max }$, and $y_{\min }<y(t)<y_{\max }$ ) to ensure that the developed model is valid at any point in the operational windows. These windows are actual working ranges of the physical shot-peening machine that are set as constraints of the process model.

To obtain the process model, the objective function of this problem is to minimize a sum of the squared error that penalizes deviation of the FOPDT model from the measurement data. The solution of the optimization problem is an optimal set of model parameters $\left(K_{p}, \tau_{p}\right.$ and $\left.\theta_{p}\right)$. Table 1 is the optimization algorithm [41]:

Table 1. The optimization algorithm.
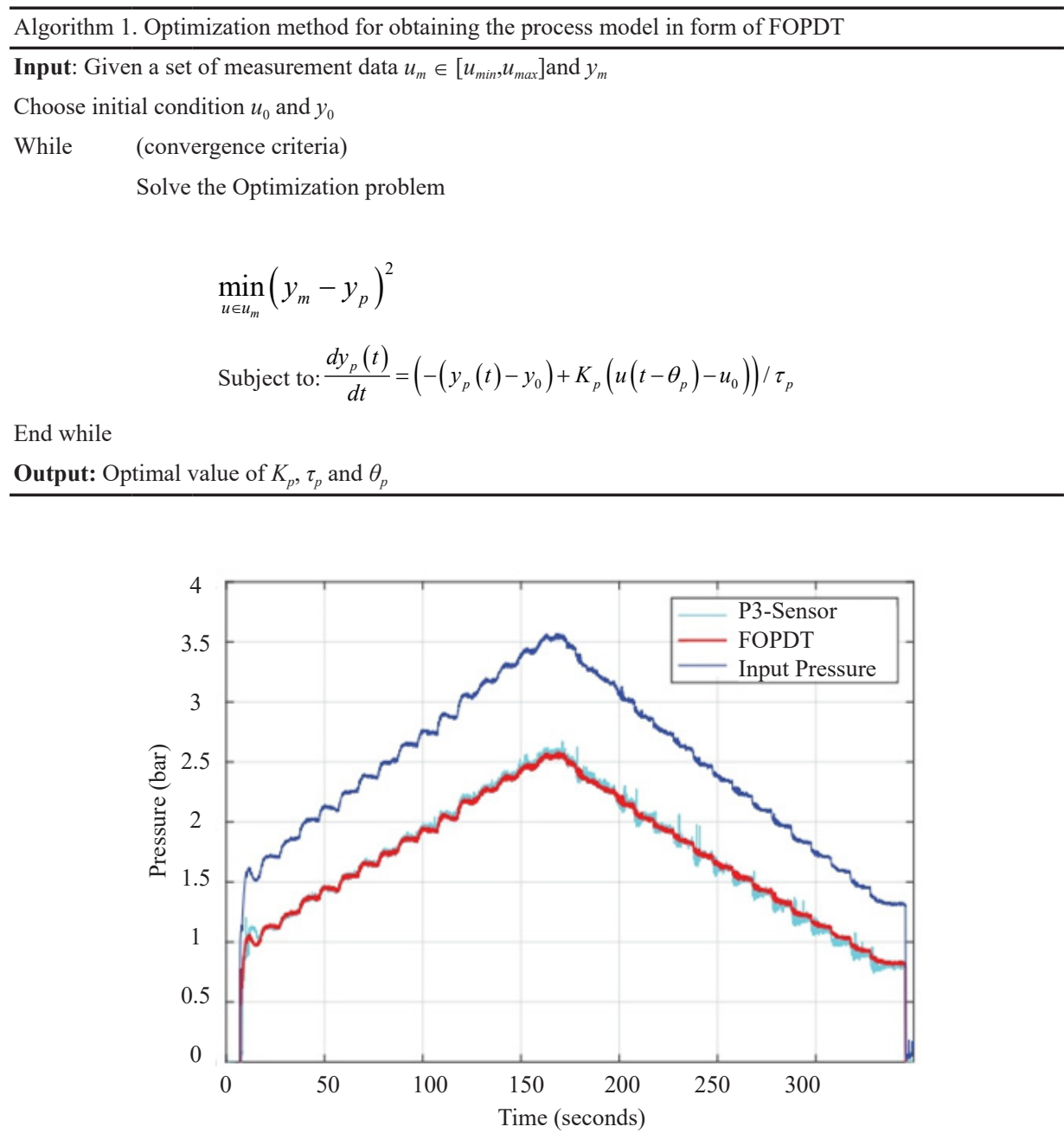

Figure 4. Comparison of the internal process model prediction (red line) and the sensor measurement data (cyan line) for the wide range of the same inlet input pressure (blue line) of ASR 230 peen type and media flow rate of $3 \mathrm{~kg} / \mathrm{min}$.

In this study, only pressure at the sensor P3 is used for process model development. This selection of the P3 sensor is chosen based on the sensor down-selection process. Once both measurement data of $u(t)$ and $y(t)$ are obtained, an internal process model is developed using the above optimization algorithm. The obtained model is benchmarked by comparing against the experimental data for the same input of $u(t)$ and the initial value of $y(0)$. Figure 4 shows a comparison of the internal process model results (red line) and sensor measurement data (cyan line) for the same inlet pressure (blue line) of the ASH 230 peen type with a media flow rate of $3 \mathrm{~kg} / \mathrm{min}$. The obtained results show that the 
developed internal process model in the form of FOPDT can accurately present the dynamical process of the shot peening machine. The obtained internal process model is then used to design the controller in subsections 2.3.

\subsection{Proxy model development with XGBOOST machine learning algorithm}

As mentioned that the proxy model is developed to translate the target setting intensity value to a reference value of the air pressure at the chosen sensor location on the nozzle for real-time feedback control and monitoring. And the XGBOOST machine learning algorithm developed in python [43] is employed to build a shot peening proxy model from sparse measurement data. This subsection only highlights the main advantages of XGBOOST machine learning algorithm. The reader can refer to [43] for more details. In addition to gradient boosting, XGBOOST is also equipped the following techniques to make six main interesting features. (1) XGBOOST provides a choice to penalize complex models using L1 and L2 regularizations, which can help to prevent the overfitting of big data. (2) XGBOOST comprises a sparsity-aware split algorithm to deal with different types of sparsity patterns in the data. This capability can handle sparse data caused by missing values. (3) XGBOOST is also integrated with the distributed weighted percentile sketch algorithm for effectively handling weighted data to consider roles of the important tree as well as data with greater accuracy. (4) XGBOOST system is designed with a data block structure, where data is sorted and stored in an efficient way in each memory unit. This block structure smoothly allows the data flow to be recalled in subsequent iterations instead of re-evaluating. The way of sorting and storing is useful for the split process as well as column sub-sampling. Thus, XGBOOST algorithm can use multiple cores for a faster computing process in model exploration. In addition, (5) XGBOOST is developed and implemented for optimal usage of the computational hardware by allocating internal buffers in each thread, where the calculated gradient statistics can be stored to allow the non-continuous memory access by row index. Moreover, (6) XGBOOST is designed with 'out-of-core' computing technique to optimize available space on the hard drive, as well as maximizes usage as working with big datasets. The followings are brief of the mathematical expressions in [43]:

For a given data set of $N$ samples and $M$ features, $D=\left\{\left(x_{i}, y_{i}\right)\right\}\left(|D|=N, x_{i} \in \mathbb{R}^{m}, y_{i} \in \mathbb{R}\right)$. A tree ensemble model uses $K$ adaptive functions to predict output(s) as

$$
\hat{y}_{i}=\phi\left(x_{i}\right)=\sum_{i=1}^{K} f_{k}\left(x_{k}\right), f_{k} \in \mathcal{F}
$$

$\mathcal{F}=\left\{f(x)=w_{q}(x)\right\}\left(q: \mathbb{R}^{m} \rightarrow T, w \in \mathbb{R}^{T}\right)$ is the space of regression trees. $q$ is the structure of each tree that maps the sample to a leaf index. $T$ is the number of leaves in each tree. In addition, $f_{k}$ corresponds to an independent tree structure $q$ and leaf weight $w$. To study the set of functions used in the model, the following minimization of the regularized objective function are employed:

$$
\mathcal{L}(\phi)=\sum_{i} \ell\left(\hat{y}_{i}, y_{i}\right)+\sum_{i} \Omega\left(f_{k}\right), \text { where } \Omega(f)=\gamma T+\frac{1}{2} \lambda\|w\|^{2} .
$$

In this expression, $\ell$ is a differentiable convex loss function that is used to measure a difference between the predictions $\hat{y}_{i}$ and targeted $y_{i}$. The term $\Omega$ is employed to penalize the complexity of the model used. The additional regularization term is added to smooth final learned weights to avoid overfitting. Intuitively, the regularized objective is defined to select a simple model employing and predictive functions.

An iterative method can also be used to minimize the objective function. Let $\hat{y}_{k}^{(t)}$ is the prediction of the $i$-th instance at the $t$-th iteration. A function $f_{t}$ is added to the following minimization problem to improve the model accuracy as

$$
\mathcal{L}(\phi)=\sum_{i=1}^{N} \ell\left(y_{i}, \hat{y}_{i}^{(t-1)}+f_{t}\left(x_{i}\right)\right)+\Omega\left(f_{t}\right)
$$

In addition, the second-order approximation is used for faster optimizing the objective as 


$$
\mathcal{L}^{(t)}=\sum_{i=1}^{N}\left[\ell\left(y_{i}, \hat{y}_{i}^{(t-1)}\right)+g_{i} f_{t}\left(x_{i}\right)+\frac{1}{2} h_{i} f_{t}^{2}\left(x_{i}\right)\right]+\Omega\left(f_{t}\right)
$$

where $g_{i}=\partial_{\left.\hat{y}_{i}^{(-1)}\right)} \ell\left(y_{i}, \hat{y}_{i}^{(t-1)}\right)$ and $h_{i}=\partial_{\hat{y}^{(t-1)}}^{2} \ell\left(y_{i}, \hat{y}_{i}^{(t-1)}\right)$ are the first and second order gradient statistics of the loss function. In this study, the constant terms are removed to obtain the following simplified objective at step $t$ as

$$
\tilde{\mathcal{L}}^{(t)}=\sum_{i=1}^{N}\left[g_{i} f_{t}\left(x_{i}\right)+\frac{1}{2} h_{i} f_{t}^{2}\left(x_{i}\right)\right]+\Omega\left(f_{t}\right)
$$

In addition, we also assume that $I L$ and $I R$ are the instance sets of left and right nodes after splitting, and $I=I L \cup$ $I R$, then the loss reduction can be expressed as

$$
\mathcal{L}_{\text {split }}=\frac{1}{2}\left[\frac{\left(\sum_{i \in I L} g_{i}\right)^{2}}{\sum_{i \in I L} h_{i}+\lambda}+\frac{\left(\sum_{i \in I R} g_{i}\right)^{2}}{\sum_{i \in I R} h_{i}+\lambda}-\frac{\left(\sum_{i \in I} g_{i}\right)^{2}}{\sum_{i \in I} h_{i}+\lambda}\right]-\gamma
$$

This formula of $\mathcal{L}_{\text {split }}$ can be used to find an optimal split at any given node. In this expression, the formula solely depends on the loss function and regularization parameter $\gamma$.

In the actual peening process, each combination set of inlet pressure, media flow rate, and peen size can be used to determine a value of peening intensity. Inversely, to determine reference pressure, the peening intensity is one of the model input variables for the proxy model construction besides the media flow rate and peen size variables. In other words, the proxy model of pressure on the nozzle is developed using XGBOOST algorithm that uses the inputs of measurement data of the media flow rate, peen size, and intensity as illustrated in Figure 5.

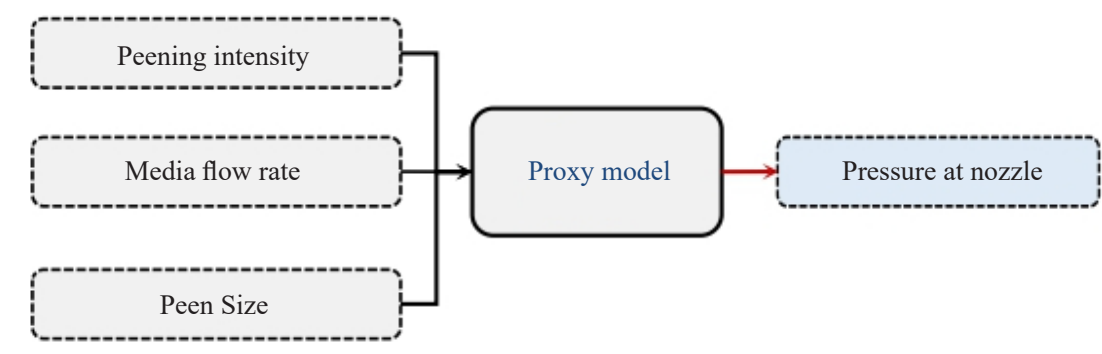

Figure 5. Input and output parameters in the current machine learning model.

In the training process, $80 \%$ of measurement data sets are randomly selected for training, while the other $20 \%$ are chosen for testing. During boosting process, tree ensembles are built sequentially so that each subsequent tree can reduce any error of the previous trees. In addition, hyperactive parameter tuning is performed using a grid search with 5 -folds of cross-validation. In total, about 6480 combinations of the hyperactive parameters are validated in the model training process. An obtained proxy model can accurately predict the reference set point of air pressure on the nozzle for any pre-defined intensity with an error of about 3\%. Comparison of prediction results against measurement data for different peen sizes of ASR 70 and ASR 230 are shown in Figures 6(a) and (b), respectively. Both the test data and training data are also used in the comparison for benchmarking the proxy model. The proxy model can predict required pressure on the nozzle very well. 


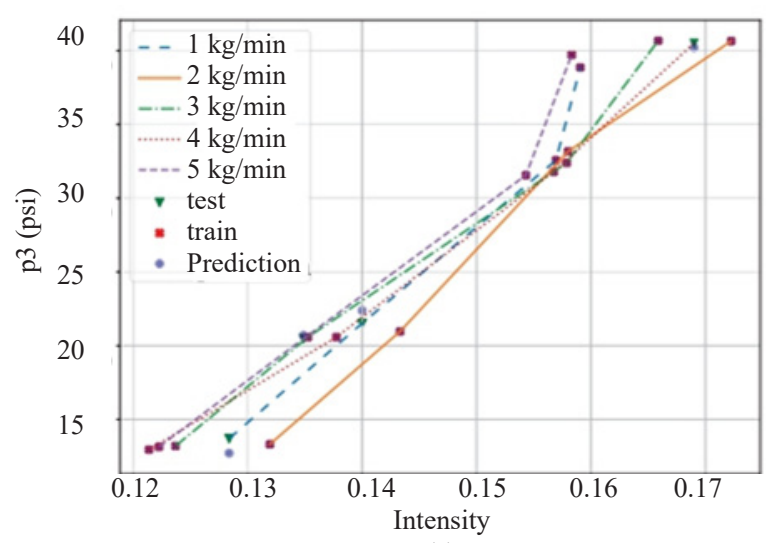

(a)

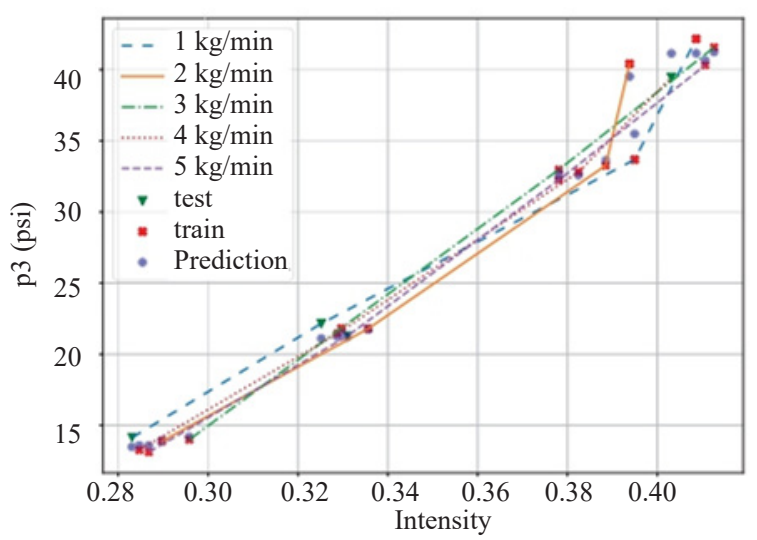

(b)

Figure 6. Comparison between the prediction of proxy model and measurement for the peen types of (a) ASR 70 and (b) ASR 230 .

\section{Control system development}

In this section, a closed-loop control system is designed based on the internal process model and PID control technology. The control system is designed to assure that control performance is stable and accurate. The developed control system also can stabilize the system instability, improve the reference tracking performance, and be able to reject the disturbances. Figure 7 shows the design of the feedback IPM-PID control system. In which, the PID controller optimally evaluates a control action for regulating the operational input to drive the dynamical process to the reference set point. The Open Platform Communication - Unified Architecture (OPC-UA) [44] transfers data between the controller and the physical shot-peening machine. The P3 pressure sensor measures pressure data at the nozzle for feedback control. The proxy model translates the expected value of intensity back to pressure reference value for real-time tracking. In addition, the Kalman filter cancels sensor measurement noise to provide an accurate signal for feedback control. The followings are the details.

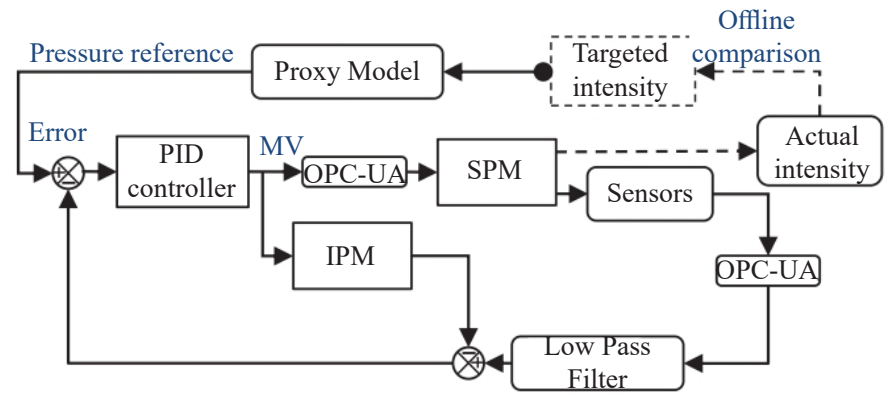

Figure 7. Closed-loop IPM - PID controller for shot peening machine.

Theoretically, the designed PID controller continuously calculates a difference between the reference set point and the measurement value of the air pressure at the nozzle. The controller also applies a correction for the inlet air pressure regulator based on designed proportional, integral, and derivative terms. A general form of PID controller is often expressed as the following: 


$$
u(t)=K_{p} e(t)+K_{I} \int_{0}^{t} e(\tau) d \tau+K_{d} \frac{d e(t)}{d t}
$$

In this expression, $u(t)$ is the manipulated variable. $e(t)$ is the difference between the actual measurement value and set point reference at time $t . K_{p}, K_{I}$, and $K_{d}$ are the gains for proportional, integral, and derivative terms, respectively. These coefficients are determined using internal process model coefficients $\left(K_{p}, \tau_{p}\right.$, and $\left.\theta_{p}\right)$ that is so-called IMC-PID control. The transfer function for the internal process model is

$$
G(s)=\frac{K_{p} e^{-\theta_{p} s}}{\tau_{p} s+1}
$$

while transfer function for the controller is

$$
C(s)=K_{C}\left(1+\frac{1}{\tau_{i} s}+\tau_{d} s\right)
$$

In which, $K_{C}, K_{I}=K_{p} / \tau_{i}$, and $K_{d}=K_{C} \tau_{d}$ are design based on internal process model parameters, please see reference [13] for more details.

For implementation, the controller is implemented using discrete sampling periods and a discrete form of the above PID equation (Equation 8), where both the integral and derivative terms need to be approximate. The discrete form of the integral term is approximated using a summation of error based on a sampling time step $(\Delta t)$ and the number of sampling instances $\left(n_{t}\right)$. In addition, the derivative term is approximated using first-order approximation method for evaluating the instantaneous slope of the process variable $(y)$. Thus, Equation 8 can be rewritten as

$$
u(t)=u_{\text {bias }}+K_{c} e(t)+\frac{K_{c}}{\tau_{I}} \sum_{i=1}^{n t} e_{i}(t) \Delta t-K_{c} \tau_{D} \frac{y_{n t}-y_{n t}-1}{\Delta t}
$$

For the control tuning, the common tuning correlations for IMC-PID control law in [13] are relatively used for our IPM-PID controller design. The IPM-PID control uses an extension of the tuning parameter $(\lambda)$ to account for the time delay. In this study, the tuning control parameters $\left(K_{C}, \tau_{l}\right.$, and $\left.\tau_{D}\right)$ are obtained by evaluating from process model parameters $\left(K_{p}, \tau_{p}, \theta_{p}\right)$, which is obtained in Section 3. Depending on controller design, we can choose aggressive tuning, moderate tuning, or conservative tuning for the shot peening process. The corresponding control parameters for each mode are defined as [41]

Aggressive tuning:

Moderate tuning:

Conservative tuning:

$$
\tau_{c}=\max \left(0.1 \tau_{p}, 0.8 \theta_{p}\right)
$$

$$
\tau_{c}=\max \left(1.0 \tau_{p}, 8.0 \theta_{p}\right)
$$

And

$$
\tau_{c}=\max \left(10 \tau_{p}, 80 \theta_{p}\right)
$$

$$
K_{c}=\frac{1}{K_{p}} \frac{\tau_{p}+0.5 \theta_{p}}{\tau_{c}+0.5 \theta_{p}}
$$




$$
\begin{gathered}
\tau_{I}=\tau_{p}+0.5 \theta_{p} \\
\tau_{D}=\frac{\tau_{p} \theta_{p}}{2 \tau_{p}+\theta_{p}}
\end{gathered}
$$

In this study, an anti-reset upwind is also implemented to ensure that the integral term does not accumulate as control output is saturated at an upper and/or lower limit. In addition, we also assume that the derivative of the reference set point $\frac{d(s p)}{d t}=0$ at any abrupt change to avoid a derivative kick as the error suddenly changes. Therefore, we can stabilize the control performance of the designed system.

To cancel the measurement noise of the pressure sensor signal during real-time feedback control, the low-pass filter technique [45] is implemented to remove high-frequency noise components. In technique, the filter is restricted to have at most two tuning parameters, yielding few optimization variables. The two chosen tuning parameters are a damping constant $\zeta$ and time constant $T_{f}$. Thus, in this study, the transfer function of the low-pass filter can be expressed in the following form [46]

$$
F_{y}(s)=\frac{1}{s^{2} T_{f}^{2}+2 \zeta T_{f} s+1}
$$

This implemented filter has a complex pole with a damping ratio of $\zeta=0.707$ [47]. The filter time constant can be incorporated into other design control parameters. The value is often chosen at $b=T_{d} / T_{f} \geq 10$ [48]. In this study, we choose $\zeta=0.707$ and $b=10$, while $T_{d}$ is the derivative time constant. The filter is integrated into the designed controller for a better pressure signal. As a result, the controller performance is then improved.

\section{Shot peening control demonstration}

In this section, both in-silico and on-site controls are performed for different scenarios to demonstrate both control performance and control accuracy. In each case, a pressure reference set point corresponding with a peening intensity is used for real-time monitoring.

\subsection{Control soft-launch demonstration}

In this subsection, the performance of the designed IPM-PID controller is compared with a conventional PID controller with a fixed set of control parameters for different control scenarios. In particular, the process model of different peen types is employed instead of the actual physical machine in the workshop. Two different peen types (ASR 70 and ASR 230) with different media flow rates (1.0, 2.0, 3.0, 4.0 and $5.0 \mathrm{~kg} / \mathrm{min})$ are used in demonstrations. Four different pressure reference set points of $0.8,2.25,2.75$, and 1.75 bars are used for online tracking. Figures 8 to 11 show the results of control soft-launch with a media flow rate of $3.0 \mathrm{~kg} / \mathrm{min}$ for peen types of ASR 70 (Figures 8 and 10) and ASR 230 (Figures 9 and 11), accordingly. Figures 8 and 9 show the results of the control system with fixed control parameters (a) and auto-tuning control parameters (b), while Figures 10 and 11 show the results of auto-tuning control system without noise filter (a) and with a low-pass filter (b). 


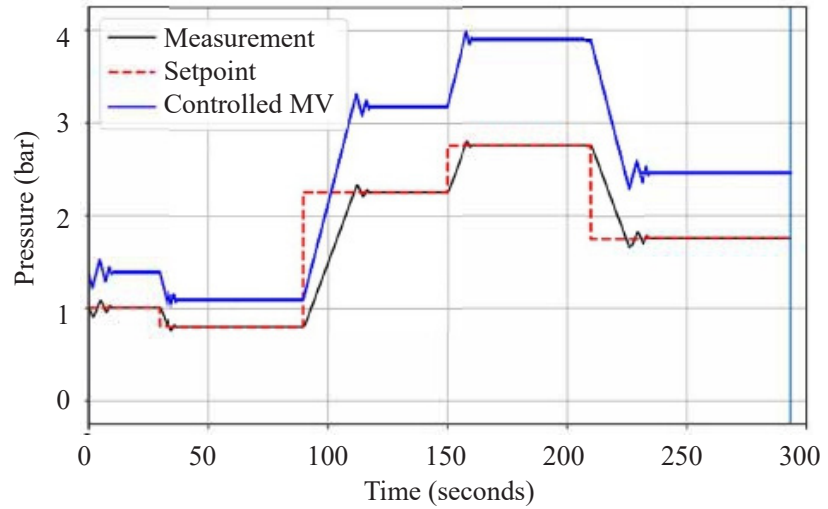

(a)

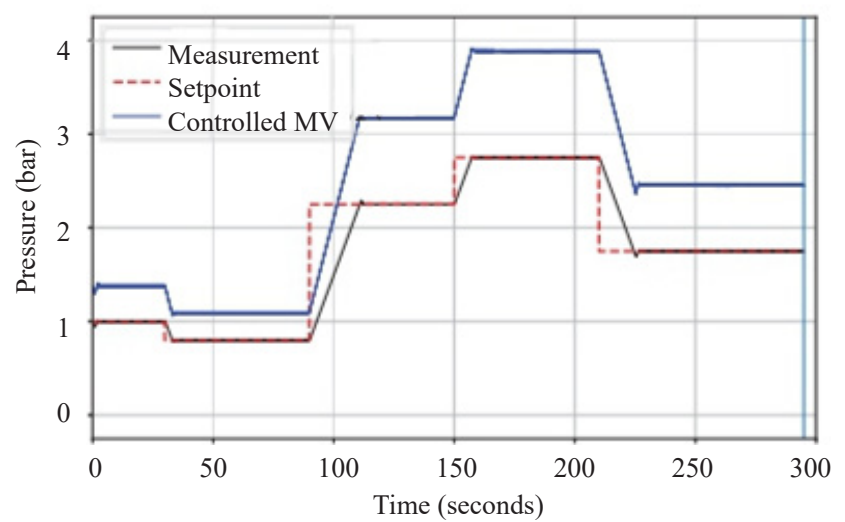

(b)

Figure 8. Comparisons of the control soft-launches of the ASR 70 peen type for different peening intensities; (a) convectional PID controller with fixed control parameters and (b) IPM-PID controller design.

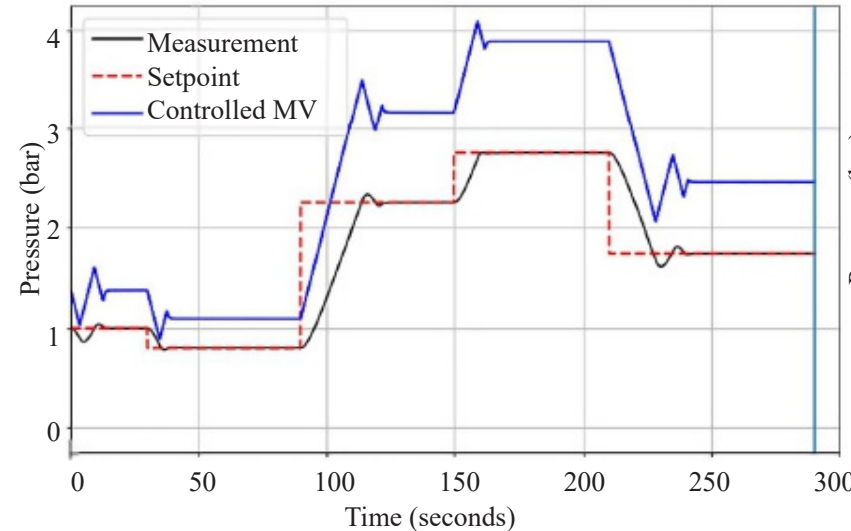

(a)

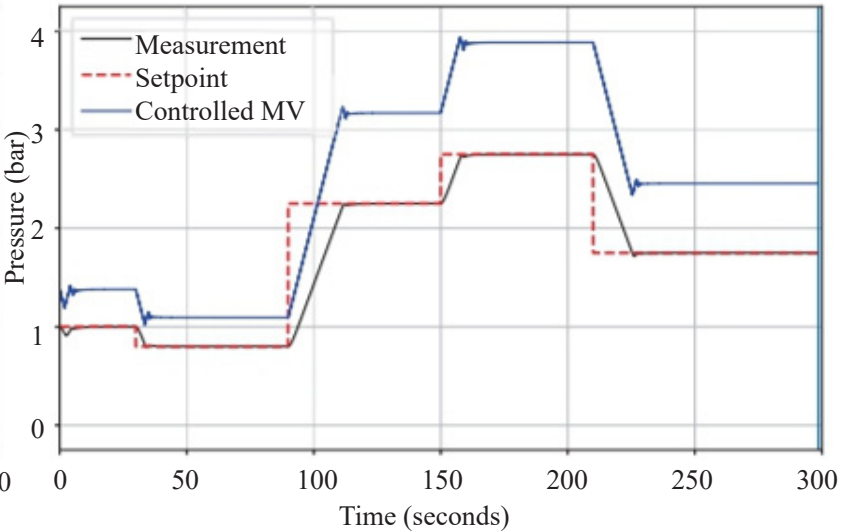

(b)

Figure 9. Comparisons of the control soft-launches of the ASR 230 peen type for different peening intensities; (a) convectional PID controller with fixed control parameters and (b) IPM-PID controller design.

Figures 8(a) and 9(a) show the result of the control design with fixed control parameters. In general, the control design gives quite good control performance. A small overshoot (less than 10\%) with some relatively small oscillations occurs at each set-point change. The pressure observation then reaches stable control status after a short duration. In fact, the controller with fixed parameters is more stable for high reference pressure as the overshot is smaller, however, it is larger for a lower reference pressure. It implies that the fixed control parameters are only valid for a certain range of reference pressure. The oscillation can occur more often since the machine often operates at different ranges of operating conditions. Therefore, these oscillations can shorten the life cycle or malfunction of the regulated valve. To improve the control performance, adaptive control parameters are needed for controller design to assure that the control system is stable and accurate for the operational range of the machine. Figures 8(b) and 9(b) express solutions of the designed controller with auto-tuning control parameters for different pressure reference set points. The obtained results indicate that the IMP-PID control is much more stable compared to the fixed parameters. There is almost no overshoot as well as an oscillation in this auto-tuning control system. It means that the designed auto-tuning algorithm works effectively for a wide range of operational conditions. 


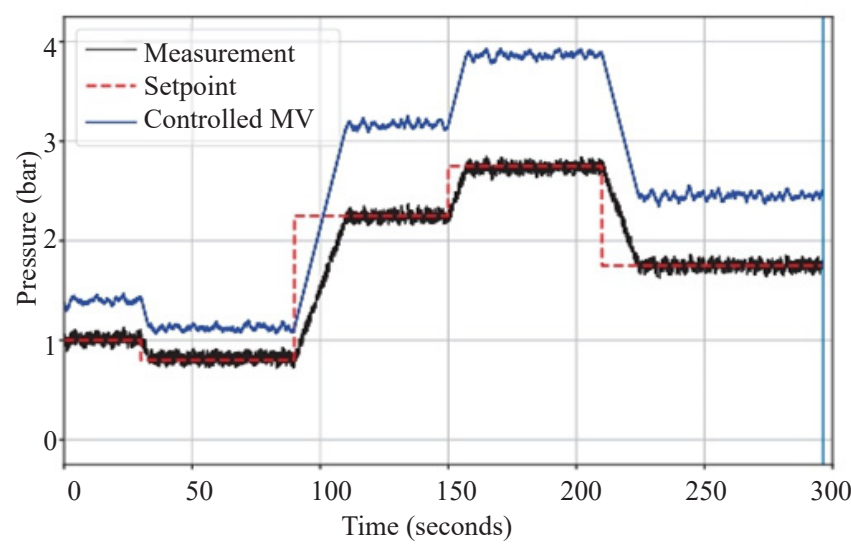

(a)

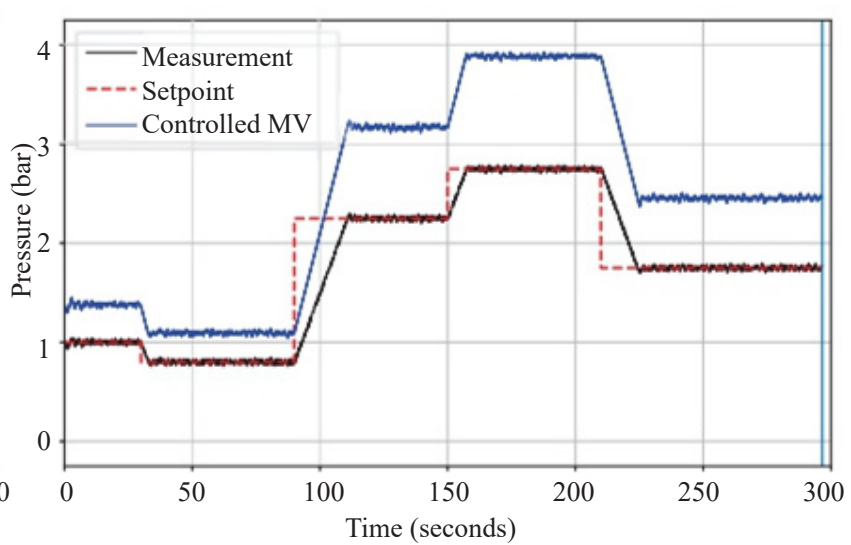

(b)

Figure 10. Comparisons of the control soft-launches of the designed IPM-PID controller for the ASR 70 peen type and different peening intensities; (a) without noise filtering and (b) with noise filtering.

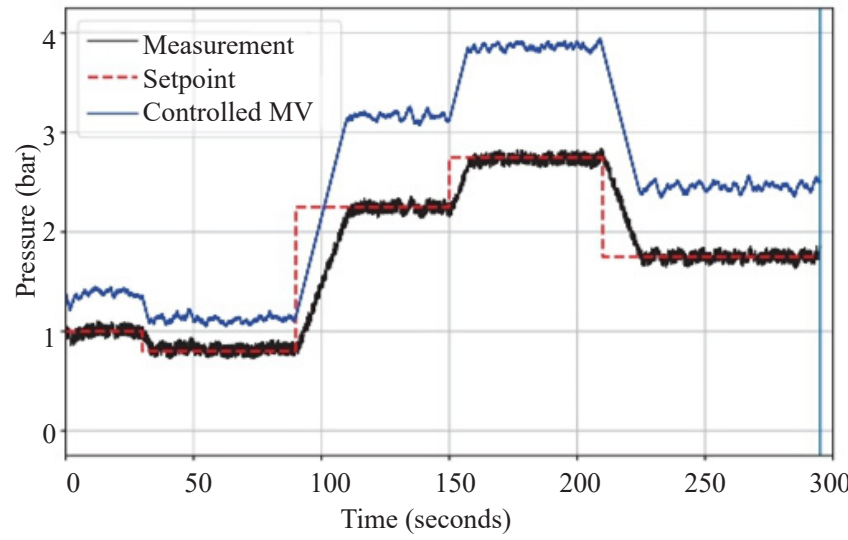

(a)

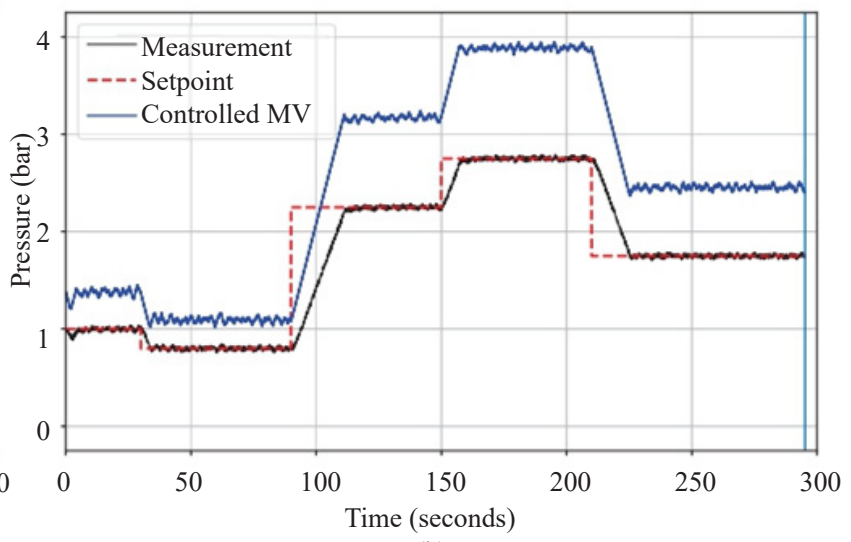

(b)

Figure 11. Comparison of control soft-launches of the designed IPM-PID controller for the ASR 230 peen type and different peening intensities; (a) without noise filtering and (b) with noise filtering.

In actual operation, sensor and/or measurement methods often obtain(s) some noises in the measurement data during the feedback control process. These noisy data strongly affect the control performance. The noise also can lead the closed-loop control system to an instability status or even failure. To study the effect of the measurement noise on control performance, white noise with zero mean and variance of 0.15 bars is added into the simulated output (simulation plant) of air pressure measurement at the nozzle. Figures 10(a) and 11(a) show control results of the auto-tuning control system without noise filter implementation, while Figures 10(b) and 11(b) show control results of the auto-tuning system with a noise filter integrated. Without noise filtering, the controller works harder to keep the observation data close to the setpoint as much as possible. Strong measurement noise causes strong oscillation in the manipulated variable. It means that the noise causes strong instabilities in controller performance, as well as loss in the control accuracy. However, with the low-pass filter integrated, almost all the noise is canceled out from measurement data. As such, a smoother mean value of the pressure measurement is obtained for feedback control. With filter integration, the control performance is much more stable and control accuracy is improved.

\subsection{On-site control demonstration}

In this section, the developed IPM-PID controller is integrated into the physical shot machine for on-site control demonstration. The on-site controls are performed using one peen type of ASR 70 to demonstrate control performance 
in actual peening operations. Fifteen on-site control scenarios are performed for different operational conditions, which covers the whole ranges of the machine capabilities (media flow rate $=[1.0-5.0] \mathrm{kg} / \mathrm{min}$, and inlet air pressure $=[0.0-54.0]$ psi). In which, three typical values of targeted intensity are set for each of five values of a media flow rate of 1.0, 2.0, 3.0, 4.0 , and $5.0 \mathrm{~kg} / \mathrm{min}$. To determine an intensity value, on-site controls are performed for at least four exposure times to measure arc heights for saturation curve plotting. In general, obtained results show that the developed control system is stable, robust, and accurate. For demonstration, Figures 12 to 17 only show details of on-site control results of 1.0 and 5.0 $\mathrm{kg} / \mathrm{min}$ for 3 different values of intensity.

Figures 12 to 14 show the results of the cases with a media flow rate of $1.0 \mathrm{~kg} / \mathrm{min}$ for different targeted intensities of $0.128,0.142$, and $0.159 \mathrm{mmA}$. Figures 12 to 14 (a) show online control with pressure monitoring of P3 in black line (upper) compared to reference set points in the red line. Three measurement sensors (P1, P2, and P3) at the nozzle are reported and plotted in these figures, however, we only use P3 for feedback control. The automatic regulated input air pressure is plotted in the blue line. Three stages are intendedly set for each on-site control scenario for clearer representation; three stages are (1) pre-control stage, (2) adjustment stage, and (3) actual exposure stage (see Figure 12(a)). In stage (1), no control is applied, as such, the machine is running with the default setup of operational inputs (e.g., the inlet pressure of $20.0 \mathrm{psi}$, media flow rate of $3.0 \mathrm{~kg} / \mathrm{min}$, etc.). The process is very unstable with a great fluctuation of inlet air pressure that leads to oscillations in pressure measurement. In stage (2), control action is applied to regulate inlet pressure automatically for driving the dynamical process and pressure at the nozzle to the default reference set point. The targeted intensity is set through the keyboard for new a pressure reference set point. The integrated control system immediately manipulates inlet air pressure to attain the new reference set point at the nozzle. A short adjustment time is often set to ensure that the peening process is stable before peening on the surface component. Stage (3) is the peening period as the shots are directly peened on the component surface. For each intensity, a relevant exposure time is set relying on nozzle transition speed as well as peening conditions. In general, the developed controller can stabilize fluctuations of inlet air pressure during the peening process. Obtained results also indicate that control performance is stable and accurate as the controller can regulate inlet air pressure to drive the process attaining different pressure reference set points.

Figures 12 to 14 (b) show the plot of saturation curves using at least four measurement points of different exposure times to determine actual peening intensity and exposure time (1T). In these figures, the values of arc height are scaled up one hundred times in the plots for clearer representation. In these figures, measurement intensities (or arc heights at exposure time (1T)) are plotted in red lines, while the arc heights at $2 \mathrm{~T}$ are plotted in green lines. The obtained intensity measurements are compared to the setting values for all the tests. All difference values are smaller than $0.005 \mathrm{mmA}$. These errors are much smaller than the industry threshold value of $\pm 0.01 \mathrm{mmA}$. In another word, the developed IPMPID control system performance is accurate.

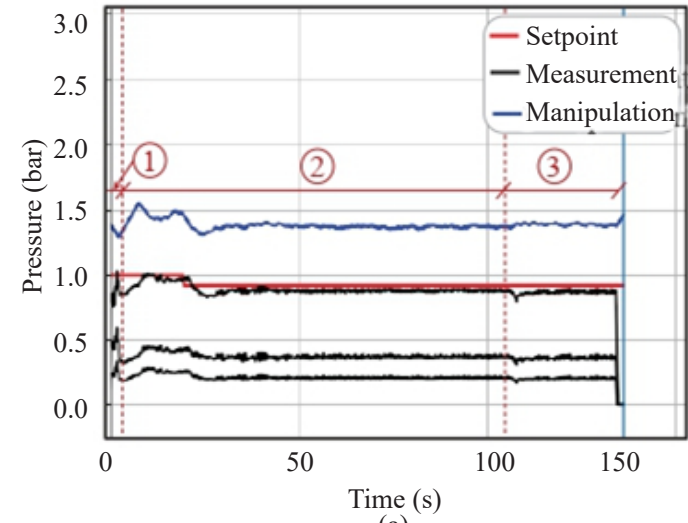

(a)

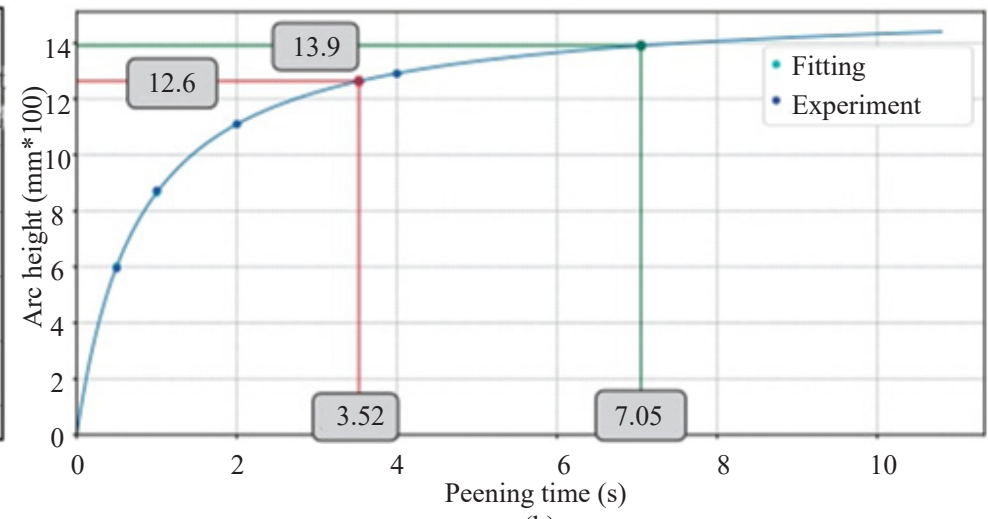

(b)

Figure 12. On-site control demonstration with a set mass flow rate of $1.0 \mathrm{~kg} / \mathrm{min}$ for ASR 70 peen type with target intensity of $0.128 \mathrm{mmA}$; (a) realtime pressure monitoring (reference set point (red-line), manipulated input pressure (blue-line), and measurement pressure (black-lines)), and (b) measurement saturation curve with an actual intensity of $0.126 \mathrm{mmA}$. 


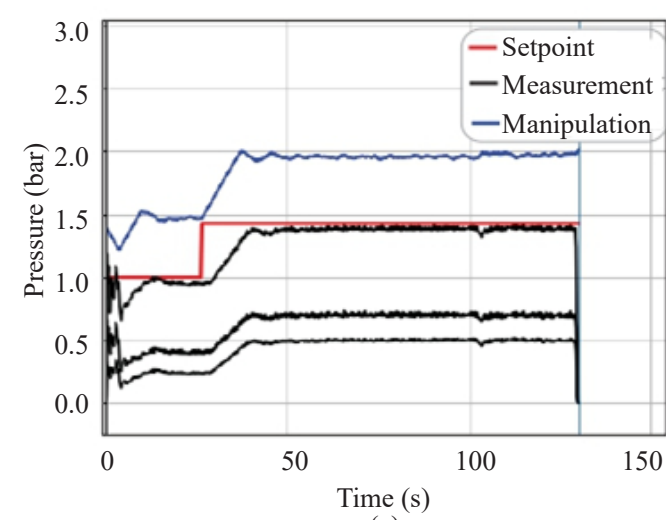

(a)

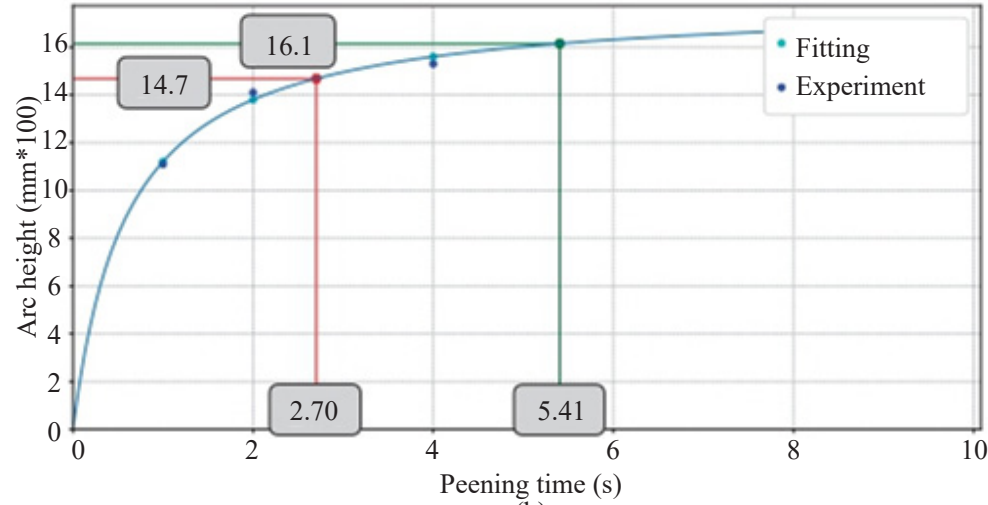

(b)

Figure 13. On-site control demonstration with set mass flow rate of $1.0 \mathrm{~kg} / \mathrm{min}$ for ASR 70 peen type with target intensity of $0.142 \mathrm{mmA}$; (a) realtime pressure monitoring (reference set point (red-line), manipulated input pressure (blue-line), and measurement pressure (black-lines)), and (b) measurement saturation curve with actual intensity of $0.147 \mathrm{mmA}$.

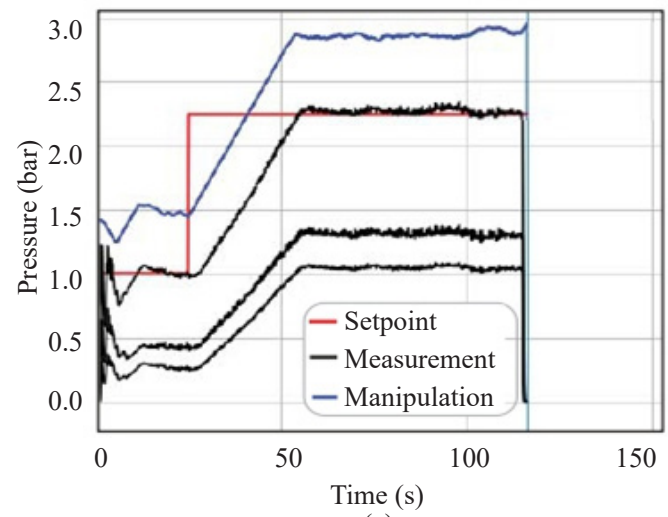

(a)

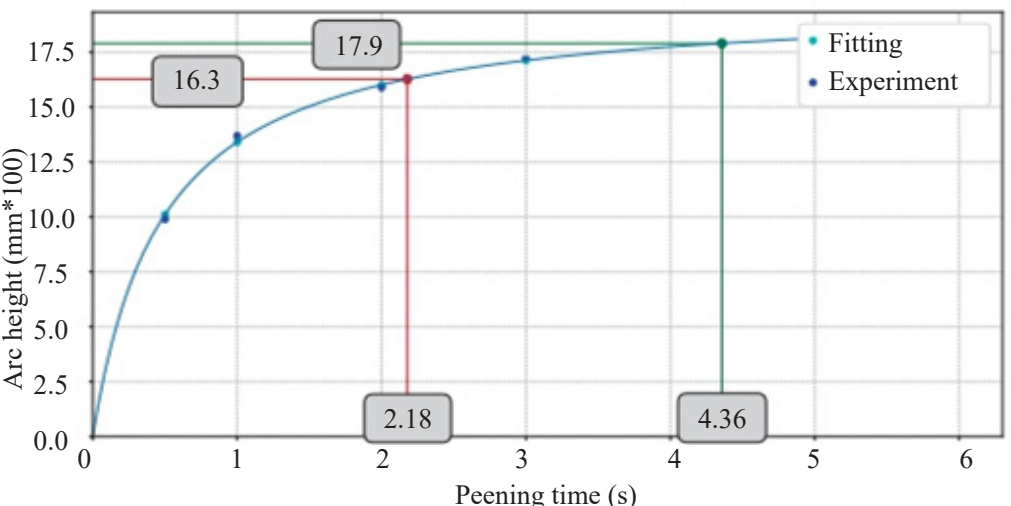

(b)

Figure 14. On-site control demonstration with a set mass flow rate of $1.0 \mathrm{~kg} / \mathrm{min}$ for ASR 70 peen type with target intensity of 0.159 mmA; (a) realtime pressure monitoring (reference set point (red-line), manipulated input pressure (blue-line), and measurement pressure (black-lines)), and (b) measurement saturation curve with an actual intensity of $0.163 \mathrm{mmA}$.

Figures 15 to 17 show the results of the on-site process controls with a media flow rate of $5.0 \mathrm{~kg} / \mathrm{min}$ for different targeted intensities of $0.121,0.138$, and $0.157 \mathrm{mmA}$, respectively. Similarly, Figures 15 to 17 (a) show real-time control with pressure monitoring of P3 plotted at the upper black line, while the pressure reference set-points are plotted in the red line and inlet air pressure in the blue line. In which, the designed IPM-PID control can automatically adjust the inlet pressure for driving pressure at P3 to meet the pressure reference set point. Three stages named (1), (2), and (3) corresponding with 'no control applied', 'adjustment time', and 'exposure time' is also presented, respectively. All control performance and system characteristics are accurate and stable, which are similar to the above expression. Also, Figures 15 to 17 (b) also show saturation curves with four actual arc height measurements. The values of arc height are also scaled up one hundred times for clearer representation. Measurement intensity (or arc height at 1T) is plotted in the red line, and the arc height at $2 \mathrm{~T}$ is in the green line. Like other media flow rate cases, differences of measurement and targeted intensity values are smaller than the industry threshold of $\pm 0.01 \mathrm{mmA}$. Generally, obtained results show that the performance of the developed IPM-PID control system is stable, robust, and accurate. It means that the developed IPM-PID control system can be used in actual peening operations to reduce cost, time, and labor in Almen system development. 


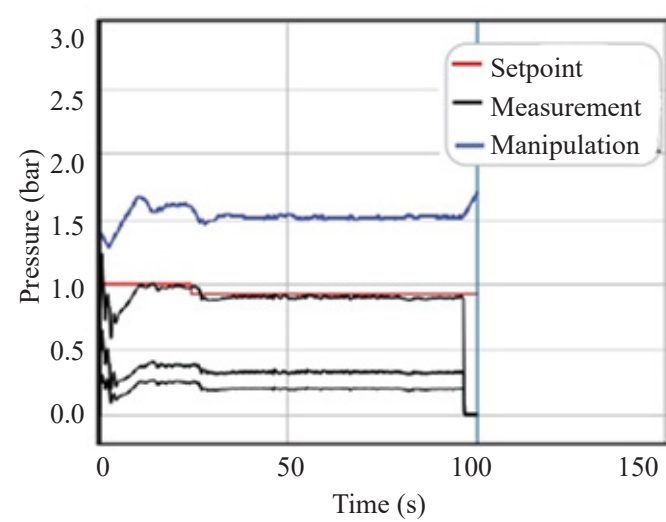

(a)

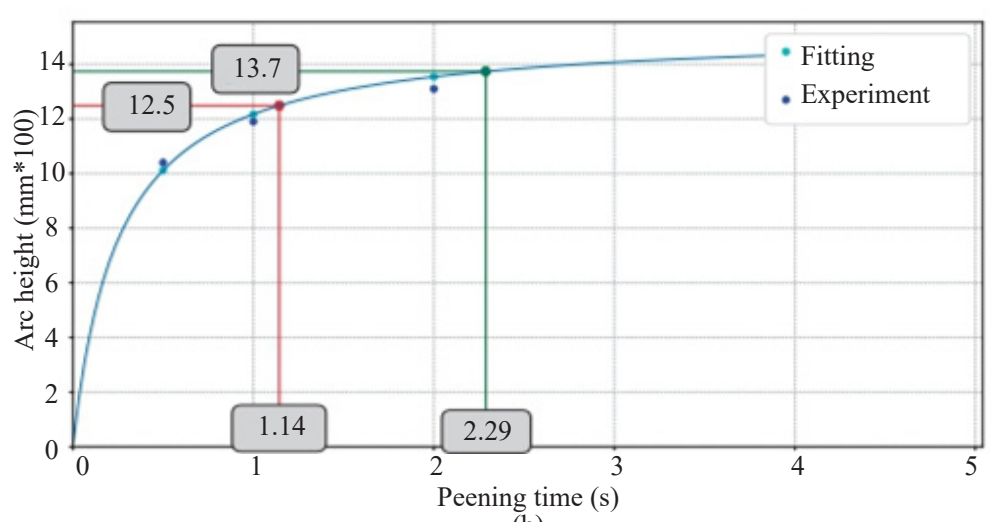

(b)

Figure 15. On-site control demonstration with a set mass flow rate of $5.0 \mathrm{~kg} / \mathrm{min}$ for ASR 70 peen type with target intensity of $0.121 \mathrm{mmA}$; (a) realtime pressure monitoring (reference set point (red-line), manipulated input pressure (blue-line), and measurement pressure (black-lines)), and (b) measurement saturation curve with an actual intensity of $0.125 \mathrm{mmA}$.

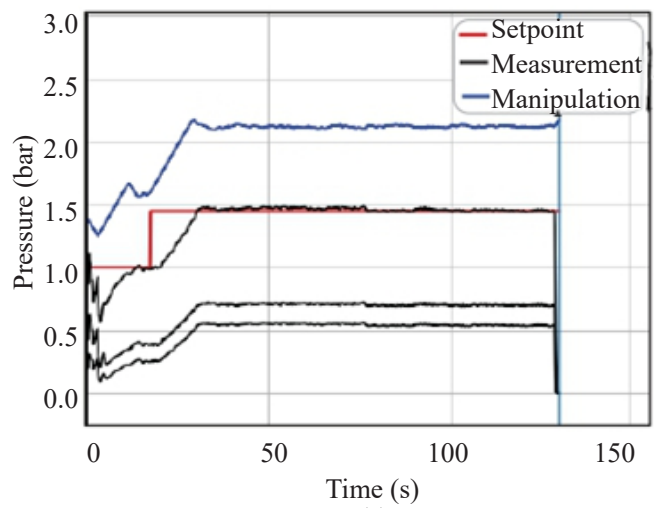

(a)

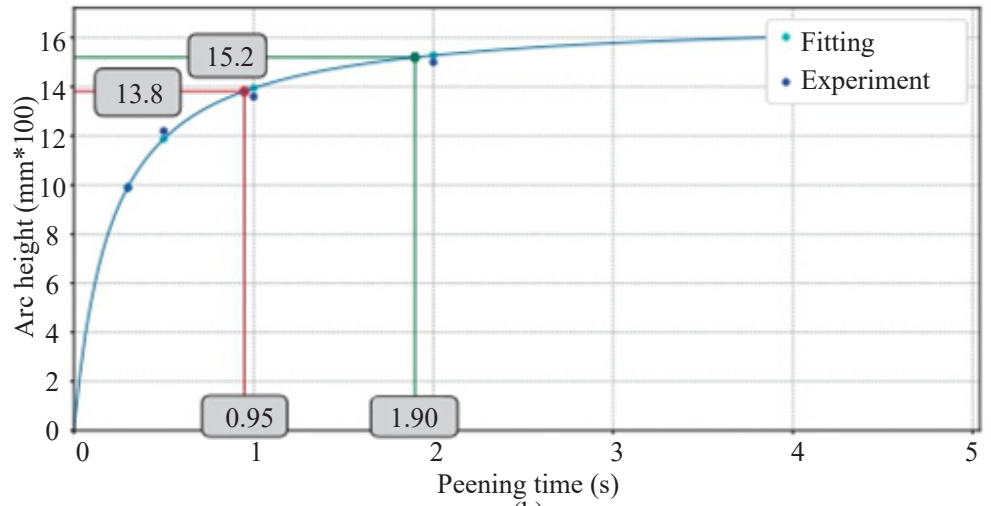

(b)

Figure 16. On-site control demonstration with a set mass flow rate of $5.0 \mathrm{~kg} / \mathrm{min}$ for ASR 70 peen type with target intensity of $0.138 \mathrm{mmA}$; (a) realtime pressure monitoring (reference set point (red-line), manipulated input pressure (blue-line), and measurement pressure (black-lines)), and (b) measurement saturation curve with an actual intensity of $0.138 \mathrm{mmA}$.

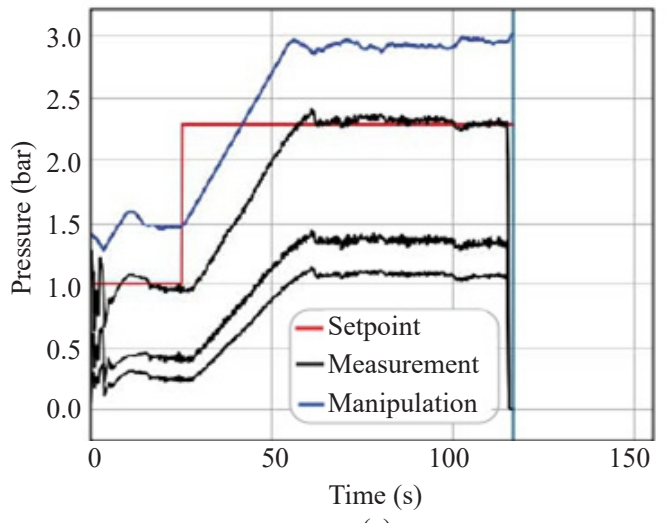

(a)

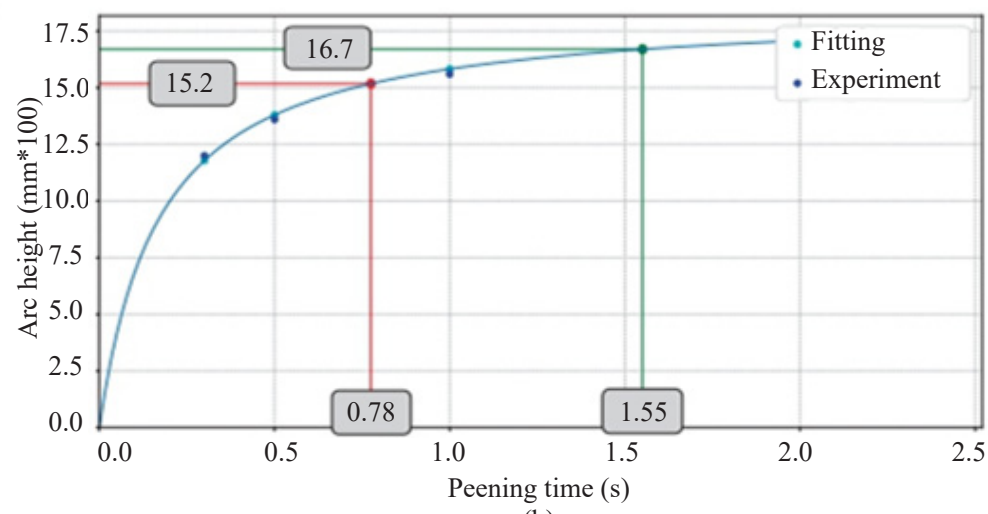

(b)

Figure 17. On-site control demonstration with a set mass flow rate of $5.0 \mathrm{~kg} / \mathrm{min}$ for ASR 70 peen type with target intensity of $0.157 \mathrm{mmA}$; (a) realtime pressure monitoring (reference set point (red-line), manipulated input pressure (blue-line), and measurement pressure (black-lines)), and (b) measurement saturation curve with an actual intensity of $0.152 \mathrm{mmA}$. 


\section{Conclusions}

In this study, a practical feedback model-based control system is developed to upgrade the current control system for a smarter and fully automated shot peening machine. This developed pressure-based control system includes an internal process model, PID controller, auto-tuning control parameters, noise filtering technique, and a proxy model. The developed control system is integrated into a physical shot peening machine for on-site control demonstration.

Performance of the developed IMP-PID control system is demonstrated using both in-silico and on-site control for different scenarios, which are designed to cover the whole range of control windows of the physical abrasive engineering (AE) shot peening machine. Both in-silico and on-site control demonstrations show that the control performance is stable, robust, and accurate. It means that the developed control system can be used for actual peening operations. In another word, the developed IPM-PID control system can significantly reduce the cost, time, and labor, as well as material waste in the development of a pre-validated Almen system for actual peening operations.

Current promising technology has been successfully applied to other shot peening machines (same type) for replication, the obtained results are very good as the based-development machine. However, the results are not included in this study. For future study, we will further develop the control system to automatically achieve both targeted intensity and coverage of industrial peening production. We also apply to other types of shot peening machine for production as it has got great attention from our industrial partners.

\section{Acknowledgement}

This project is supported by the A*STAR Science and Engineering Research Council (SERC), under its RIE2020 Advanced Manufacturing and Engineering IAF-PP Programme (Grant No: A1894a0032)

\section{Conflict of interest statement}

There is no conflict of interest for this study.

\section{References}

[1] Marsh KJ. Shot peening: techniques and applications. London: Engineering Materials Advisory Service Ltd.; 1993.

[2] Wang S, Li Y, Yao M, Wang R. Compressive residual stress introduced by shot peening. The Journal of Materials Processing Technology. 1998; 73(1-3): 64-73. Available from: doi: 10.1016/S0924-0136(97)00213-6.

[3] Meguid SA, Shagal G, Stranart JC. Finite element modelling of shot-peening residual stresses. The Journal of Materials Processing Technology. 1999; 92-93: 401-404. Available from: doi: 10.1016/S0924-0136(99)00153-3.

[4] Nguyen VB, Poh HJ, Zhang YW. Predicting shot peening coverage using multiphase computational fluid dynamics simulations. Journal of Powder Technology. 2014; 256:100-112. Available from: doi: 10.1016/j.powtec.2014.0.

[5] Taro M, Chaise T, Nélias D. A methodology to predict the roughness of shot peened surfaces. The Journal of Materials Processing Technology. 2015; 217: 65-76. Available from: doi: 10.1016/j.jmatprotec.2014.10.016.

[6] Chaise T, Li J, Nélias D, Kubler R, Taheri S, Douchet G, et al. Modelling of multiple impacts for the prediction of distortions and residual stresses induced by ultrasonic shot peening (USP). The Journal of Materials Processing Technology. 2012; 212(10): 2080-2090. Available from: doi: 10.1016/j.jmatprotec.2012.05.005.

[7] Kirk D. Peening Intensity True Meaning and Measurement Strategy. The Shot Peener. 2016; 30(3): 26-30. Available from: https://www.shotpeener.com/library/pdf/2016030.pdf.

[8] Champaigne J. Shot Peening Intensity Measurement. The Shot Peener. 1992; 6 (4):1-6. Available from: https:// www.shotpeener.com/library/pdf/1992082.pdf.

[9] McMillan GK. Industrial Applications of PID Control. In: Vilanova R, Visioli A. (eds) PID Control in the Third Millennium, Advances in Industrial Control. London: Springer; 2012. Available from: doi: 10.1007/978-1-44712425-2.

[10] Xia C, Pan Z, Polden J, Li H, Xu Y, Chen S, et al. A review on wire arc additive manufacturing: Monitoring, 
control and a framework of automated system. Journal of Manufacturing Systems. 2020; 57: 31-45. Available from: doi: 10.1016/j.jmsy.2020.08.008.

[11] Wang T, Kwok TH, Zhou C, Vader S. In-situ droplet inspection and closed-loop control system using machine learning for liquid metal jet printing. Journal of Manufacturing Systems. 2018; 47: 83-92. Available from: doi.: 10.1016/j.jmsy.2018.04.003.

[12] Xiong J, Yin Z, Zhang W. Closed-loop control of variable layer width for thin-walled parts in wire and arc additive manufacturing. The Journal of Materials Processing Technology. 2016; 233: 100-106. Available from: doi: 10.1016/j.jmatprotec.2016.02.021.

[13] Rivera DE, Morari M, and Skogestad S. Internal model control: PID controller design. Industrial \& Engineering Chemistry Process Design and Development. 1986; 25 (1): 252-265. Available from: doi: 10.1021/i200032a041.

[14] Sanders CF, Hounslow MJ, Doyle III FJ. Identification of models for control of wet granulation. Journal of Powder Technology. 2009; 188(3): 255-263. Available from: doi: 10.1016/j.powtec. 2008.05.005.

[15] Huang Y, Yuan Y, Yang L, Wu D, Chen S. Real-time monitoring and control of porosity defects during arc welding of aluminum alloys. The Journal of Materials Processing Technology. 2020; 286:116832. Available from: doi: 10.1016/j.jmatprotec.2020.116832.

[16] Aboelela MAS, Ahmed MF, Dorrah HT. Design of aerospace control systems using fractional PID controller. Journal of Advanced Research. 2012; 3(3): 225-232. Available from: doi: 10.1016/j.jare.2011.07.003.

[17] Hrovat D and Sun J. Models and control methodologies for IC engine idle speed control design. Control Engineering Practice. 1997; 5(8): 1093-1100. Available from: doi: 10.1016/S0967-0661(97)00101-9.

[18] Åström KJ. Theory and applications of adaptive control—A survey. Automatica. 1983; 19(5): 471-486. Available from: doi: 10.1016/0005-1098(83)90002-X

[19] Åström KJ and Hägglund T. Automatic tuning of simple regulators with specifications on phase and amplitude margins. Automatica. 1984; 20(5): 645-651. Available from: doi: 10.1016/0005 -1098(84)90014-1.

[20] Balan K. Control systems in shot peening - a discussion. The Shot Peener. 2014; 28(2): 22-28. Available from: https://www.shotpeener.com/library/pdf/2014017.pdf

[21] Wand WM and Rajurkar KP. Modeling and adaptive control of EDM systems. Journal of Manufacturing Systems. 1992; 11(5): 334-345. Available from: doi: 10.1016/0278-6125(92)90062-K.

[22] Schei TS. Automatic tuning of PID controllers based on transfer function estimation. Automatica. 1994; 30(12): 1983-1989. Available from: doi: 10.1016/0005-1098(94)90060-4.

[23] Nishikawa Y, Sannomiya N, Ohta T, Tanaka H. A method for auto-tuning of PID control parameters. Automatica. 1984; 20(3): 321-332. Available from: doi: 10.1016/0005-1098(84)90047-5.

[24] Cheol WL. On-line model identification for the machining process based on multirate process data. Journal of Manufacturing Systems. 2020; 56: 622-630. Available from: doi: 10.1016/j.jmsy.2020.04.006.

[25] Zhao ZY, Tomizuka M, Isaka S. Fuzzy gain scheduling of PID controllers. IEEE Transactions on Systems, Man, and Cybernetics. 1993; 23(5): 1392-1398. Available from: doi: 10.1109/21.260670.

[26] Veselý V, Ilka A. Gain-scheduled PID controller design. Journal of Process Control. 2013; 23(8): 1141-1148. Available from: doi: 10.1016/j.jprocont.2013.07.002.

[27] Thabet H, Ayadi M, Rotella F. Design of adaptive PID controllers based on adaptive Smith predictor for ultralocal model control. International Journal of Automation and Control. 2017; 11(2): 222-238. Available from: doi: 10.1504/IJAAC.2017.083311.

[28] Chertovskikh PA, Seredkin AV, Gobyzov OA, Styuf AS, Pashkevich MG, Tokarev MP. An adaptive PID controller with an online auto-tuning, by a pre-trained neural network. Journal of Physics: Conference Series. 2019; 1359(1). Available from: doi: 10.1088/1742-6596/1359/1/012090.

[29] Kramer B, Peherstorfer B, Willcox K. Feedback Control for Systems with Uncertain Parameters Using OnlineAdaptive Reduced Models. SIAM Journal on Applied Dynamical Systems. 2017; 16(3): 1563-1586. Available from: doi: $10.1137 / 16 \mathrm{M} 1088958$.

[30] He SZ, Tan S, Xu FL, Wang PZ. Fuzzy self-tuning of PID controllers. Fuzzy Sets and Systems. 1993; 56(1): $37-46$. Available from: doi: 10.1016/0165-0114(93)90183-I.

[31] Chang WD, Hwang RC, Hsieh JG. A multivariable on-line adaptive PID controller using auto-tuning neurons. Engineering Applications of Artificial Intelligence. 2003; 16(1): 57-63. Available from: doi: 10.1016/S09521976(03)00023-X.

[32] Poulin E, Pomerleau A, Desbiens A, and Hodouin D. Development and evaluation of an auto-tuning and adaptive PID controller. Automatica. 1996; 32(1): 71-82. Available from: doi: 10.1016/0005-1098(95)00105-0.

[33] Miao HY, Larose S, Perron C, and Lévesque M. An analytical approach to relate shot peening parameters to 
Almen intensity. Surface and Coatings Technology. 2010; 205(7): 2055-2066. Available from: doi: 10.1016/ j.surfcoat.2010.08.105.

[34] Guagliano M. Relating Almen intensity to residual stresses induced by shot peening: A numerical approach. The Journal of Materials Processing Technology. 2001; 110(3): 277-286. Available from: doi: 10.1016/S09240136(00)00893-1.

[35] George PM, Pillai N, Shah N. Optimization of shot peening parameters using Taguchi technique. The Journal of Materials Processing Technology. 2004; 153-154: 925-930. Available from: doi: 10.1016/j.jmatprotec.2004.04.159.

[36] Garcia CE, Morari M. Internal model control: 1. A unifying review and some new results. Industrial \& Engineering Chemistry Process Design and Development. 1982; 21(2): 308-323. Available from: doi: 10.1021/i200017a016.

[37] Garcia CE, Morari M. Internal model control: 2. Design procedure for multivariable systems. Industrial \& Engineering Chemistry Process Design and Development. 1985; 24(2): 472-484. Available from: doi: 10.1021/ i200029a043.

[38] Economou CG, Morari M, Palsson BO. Internal Model Control: extension to nonlinear system. Industrial \& Engineering Chemistry Process Design and Development. 1986; 25(2): 403-411. Available from: doi: 10.1021/ i200033a010.

[39] Cheng C, Chiu MS. Adaptive IMC Controller Design for Nonlinear Process Control. Chemical Engineering Research and Design. 2007; 85(2): 234-244. Available from: doi: 10.1205/cherd06071.

[40] Desrochers AA. A general technique for process modeling. Journal of Manufacturing Systems. 1985; 4(2): 195196. Available from: doi: 10.1016/0278-6125(85)90026-3.

[41] Brunton S, Kutz J. Data-Driven Science and Engineering: Machine Learning, Dynamical Systems, and Control. Cambridge University Press; 2019. Available from: doi: 10.1017/9781108380690.

[42] Petri KL, Billo R, Bidanda B. A neural network process model for abrasive flow machining operations. Journal of Manufacturing Systems. 1998; 17(1): 52-64. Available from: doi: 10.1016/S0278-6125(98)80009-5.

[43] Chen T, Carlos G. XGBoost: a scalable tree boosting system. In Proceedings of the 22nd ACM SIGKDD. International Conference on Knowledge Discovery and Data Mining - KDD 16. ACM Press; 2016; 785-794. Available from: doi: 10.1145/2939672.2939785.

[44] Leitner SH, Mahnke W. OPC UA - Service-oriented Architecture for Industrial Applications. SoftwaretechnikTrends. 2006; 48: 61-66. Available from: https://pi.informatik.uni-siegen.de/stt/26_4/01_Fachgruppenberichte/ ORA2006/07_leitner-final.pdf.

[45] Moschytz GS. Active Filter Design Techniques. In: Ron Mancini and Bruce Carter (eds) Analog Circuit Theory and Filter Design in the Digital World. Cham: Springer; 2019. Available from: doi: 10.1007/978-3-030-00096-7_10.

[46] Hägglund T. Signal Filtering in PID Control. IFAC Proceedings Volumes. 2012; 45(3): 1-10. Available from: doi: 10.3182/20120328-3-IT-3014.00002.

[47] Larsson P, Hägglund T. Control signal constraints and filter order selection for PI and PID controllers. In Proceedings of the 2011 American Control Conference. IEEE; 2011; 4994-4999. Available from: doi: 10.1109/ ACC.2011.5991112.

[48] Kristiansson B, Lennartson B. Evaluation and simple tuning of PID controllers with high-frequency robustness. Journal of Process Control. 2006; 16(2): 91-102. Available from: doi: 10.1016/j.jprocont.2005.05.006. 